\title{
Os impactos da tecnologia de mulching utilizada no cultivo do melão na região de Mossoró
}

\author{
The impacts of mulching technology used in melon cultivation in Mossoró region \\ Geruzia Marques Teodoro Queiroga ${ }^{1}$, Maressa Laíse Reginaldo de Sousa², Janne Kléia da Silva ${ }^{3}$, Débora Nair Jales \\ Rodrigues $^{4}$, Elisabete Stradiotto Siqueira ${ }^{5}$
}

Resumo: A tecnologia de mulching é uma ferramenta que possibilita a redução de gastos para os produtores no tocante a utilização de agroquímicos, água de irrigação e a utilização de mão-de-obra, além de promover melhoria na qualidade da fruta produzida e o aumento da produção. O presente trabalho objetivou avaliar os impactos provocados pelo uso do mulch no meio ambiental, social e econômico de uma comunidade rural de Mossoró/RN. Fez-se o uso de observações, entrevista semiestruturada e questionário estruturado, o qual foi aplicado a 12,5\% dos participantes de um total de 32 . Os resultados mostram que essa tecnologia é utilizada por todos os produtores, com o intuito de melhorar a produção do melão em quantidade e qualidade. Contudo, o uso do mulch de polietileno, utilizado nessa técnica, acarreta preocupações quanto ao seu descarte pós-uso, com a utilização de práticas arcaicas como as queimadas que afetam de forma gradual a saúde do trabalhador e as propriedades biológicas do solo.

Palavras-chave: impactos ambientais, impactos sociais, impactos econômicos

\begin{abstract}
The mulching technology is a tool that enables cost reduction for producers regarding the use of agrochemicals, irrigation water and the use of labor force, promoting improvement in the produced fruit quality and increasing production. The present study aimed to evaluate the impacts caused by the use of mulch in the environmental, social and economic environment of a rural community of Mossoró / RN. Observation, semi-structured interview and structured questionnaire were used in the study, and the questionnaire was applied to $12.5 \%$ of participants from a total of 32 . The results show that this technology is used by all producers, in order to improve the production of melon in quantity and quality. However, the use of polyethylene mulch utilized therein causes concern as to their post-use disposal, with the use of archaic practices, such as burning, that gradually affect workers' health and biological properties of the soil.
\end{abstract}

Key words: environmental impacts, social impacts, economic impacts

\footnotetext{
*Autor para correspondência

Recebido para publicação em 05/05/2015; aprovado em 14/07/2015

${ }^{1}$ Mestre em Ambiente, Tecnologia e Sociedade, Universidade Federal Rural do Semi-Àrido, Mossoró; 0849 9973-0474, geruzia_mtq@ yahoo.com.br

${ }^{2}$ Mestre em Ambiente, Tecnologia e Sociedade, Universidade Federal Rural do Semi-Àrido, Mossoró, maressalaise@gmail.com

${ }^{3}$ Mestre em Ambiente, Tecnologia e Sociedade, Universidade Federal Rural do Semi-Àrido, Mossoró, jannemacelino@ hotmail.com

${ }^{4}$ Mestre em Ambiente, Tecnologia e Sociedade, Universidade Federal Rural do Semi-Àrido, Mossoró, deboranjr@gmail.com

${ }^{5}$ Professora Doutora da Universidade Federal Rural do Semi-Àrido, Mossoró, betebop@uol.com.br
} 


\section{INTRODUÇÃO}

Nos últimos anos, o planeta Terra vem sofrendo com as transformações ambientais causadas pela atividade agrícola e pela pecuária. Estas práticas provocam impactos sobre o ambiente, tais como desmatamentos e expansão da fronteira agrícola, queimadas em pastagens e florestas, poluição por dejetos animais e agrotóxicos, erosão e degradação de solos, desertificação e contaminação das águas, sendo que as consequências desses impactos podem acarretar em diminuição da diversidade biológica, perda de variedades, extinção de espécies e populações, entre outros (LEITE et al., 2011).

De acordo com Araújo (2010), uma das principais ameaças ao meio ambiente não é a expansão da fronteira agrícola, mas a tendência à monocultura, ao uso de agrotóxicos e a consequente extinção de sistemas tradicionais de cultivo. Somando-se a isso, surgem as implementações do setor, favorecidas pela tecnologia que, se volta para o aumento da produção sem uma preocupação prévia no sentido de conter agressões ao meio ambiente, bem como, a todo o contexto que o envolve.

Embora o processo de modernização da agricultura traga alguns problemas, não se pode negar que esse setor é de grande importância para a economia do país, e em muitas regiões ainda é a principal fonte de renda para muitas famílias. De modo que na região Nordeste, o agronegócio segue um ritmo crescente, e isso pode ser observado pela expansão do consumo de frutas in natura, entre elas o melão, em países europeus para onde são exportados (BEZERRA, 2012).

A cultura do melão (Cucumis melo L.) que teve o Estado do Rio Grande do Sul como o indutor da produção no Brasil foi estimulada pela modernização da agricultura, a partir dos anos 70, com um considerável incremento na produção, através da aplicação de tecnologias, insumos e financiamentos (BRAGA SOBRINHO et al., 2008), passando a ser cultivado também em Pernambuco (PE) e na Bahia (BA) (DIAS, 2014). Na década de 90, o melão se estabeleceu como cultura importante para o semiárido nordestino.

A região Nordeste é a principal produtora de melão do Brasil (CAMPELO et al., 2014; FREITAS et al., 2014), abrange aproximadamente $87 \%$ da área cultivada e participa com 95\% da produção nacional (SOUSA et al., 2012; DANTAS et al., 2013), com destaque para o Rio Grande do Norte (Vale do Açu/Mossoró) e Ceará (Aracati/Chapada do Apodi) responsáveis por $95 \%$ da produção da região, segundo Aragão e Ávila (2003). O melão foi o fruto brasileiro mais exportado em 2012, com 181,7 mil toneladas, tendo o Rio Grande do Norte na liderança nacional (IBGE, 2012).

Braga Sobrinho et al., (2008), explicam que todo esse crescimento deve-se às excelentes características edafoclimáticas da região para o desenvolvimento dessa cultura, de modo que a região de Mossoró é um dos líderes no ranking de exportação de melão (BEZERRA, 2012).

Quanto ao uso de tecnologias para aumentar a produção e melhorar a qualidade da fruta produzida, entre outras, é utilizada a técnica do cultivo protegido a partir do uso de mulch para cobertura de solo, técnica em que se coloca um filme de polietileno com espessura entre 10 e 50 micra e largura de até 3 metros, em toda a área cultivada que receberá a semente da fruta servindo de cobertura morta (MORAIS, 2006; FIGUEIREDO; LEITE, 2011).

Mulch, segundo o vocabulário de Ciência do Solo, é qualquer material tal como palha, serragem, plástico, etc. que é espalhado na superfície do terreno com a finalidade de proteger o solo, corrobora Rosenberg (1974). De acordo com Morais (2006), existe uma variedade de filmes de polietileno tais como: filmes opacos pretos, transparentes, cinza, verde, marrom, amarelo e prateado, que dependendo da coloração, opacidade ou transparência, podem apresentar maior ou menor capacidade de transmitir radiações caloríficas e dessa forma, os diferentes tipos de mulch modificam as condições edafoclimáticas dependendo das propriedades ópticas dos materiais e do tipo de solo.

Se por um lado o mulch é uma vantagem, por outro lado, representa um sério problema ecológico, à medida que vai se acumulando ao longo do tempo na natureza, pois este é um material difícil de compactar e gera um grande volume de lixo que passa a ocupar muito espaço no ambiente dificultando assim a decomposição de outros materiais orgânicos. É resistente aos decompositores, fungos e bactérias, e por este motivo tem uma degradação muito lenta. Quando colocado em contato direto com o meio ambiente demora aproximadamente 100 mil anos para se decompor, a partir daí os problemas em descartar o plástico começam a surgir (MACHADO, 2011).

Nesse contexto, o estudo se justifica a partir da necessidade e preocupação em se debater prejuízos provenientes da tecnologia de mulching, ao passo que se desperta para a busca de soluções que revertam possível impacto ao meio ambiente e a saúde dos envolvidos, bem como, melhores condições de desenvolvimento da comunidade em questão, a qual se destaca na produção e exportação de melão, tendo sido a primeira no mundo a ser certificada pelo selo Fair Trade (Comércio Justo) para essa cultura, de acordo com o Serviço Brasileiro de Apoio às Micro e Pequenas Empresas do Estado do Rio Grande do Norte (ARAÚJO, 2009).

O objetivo desse estudo foi avaliar os impactos no âmbito ambiental, social e econômico gerados pela técnica do cultivo protegido a partir do uso de mulch sintético para cobertura de solo, tendo-se como objeto de estudo a comunidade referida, na zona rural de Mossoró.

\section{MATERIAL E MÉTODOS}

\section{Tipo de pesquisa}

O estudo foi realizado a partir de uma pesquisa de campo em uma comunidade rural, localizada a aproximadamente $30 \mathrm{~km}$ de Mossoró, a qual é constituída por 32 famílias, organizada em uma sociedade cooperativa.

\section{Sujeitos da pesquisa}

A sociedade cooperativa é composta por 32 participantes, no entanto, apenas $12,5 \%$ desse total se dispuseram a participar da pesquisa. Os participantes tinham idade igual ou superior a 18 anos e de ambos os sexos.

\section{Instrumento de coleta de dados}

Em um primeiro momento foram realizadas visitas, em que se observou a geografia local, o manejo empregado na cultura do melão, a dinâmica ambiental, no que diz respeito 
aos cuidados com o ambiente de trabalho como um todo, além de uma entrevista semiestruturada, com o líder da cooperativa, abrangendo desde um breve histórico sobre o surgimento da mesma, o tipo de estrutura fundiária, com relação à conduta quanto ao uso de defensivos agrícolas, se existia recuperação de áreas degradadas, que tipo de tecnologia era utilizada para diminuir a evapotranspiração da cultura, até a conquista do selo de comércio justo, cujo objetivo desta foi obter informações para a elaboração de uma temática a ser trabalhada na comunidade.

Em um segundo momento foi aplicado um questionário estruturado para atender ao objetivo proposto nessa pesquisa, com perguntas objetivas a respeito da faixa etária, escolaridade, profissão, quanto ao uso do mulch na atividade agrícola, sua especificação, há quanto tempo fazia uso do mesmo, se é retirado completamente da terra, o que é feito do resíduo, qual a melhoria que a tecnologia trouxe e que tipo de relação existia entre os cooperados e as empresas de reciclagem.

$\mathrm{O}$ mesmo permitiu traçar o perfil do produtor entrevistado, colher informações sobre o conhecimento dos mesmos com relação à tecnologia de mulching, verificar por quanto tempo esse filme vem sendo utilizado nas áreas de produção referidas, como se dá o seu descarte após a colheita da fruta e, quais as vantagens que essa tecnologia trouxe como formas de melhorias dentro de suas realidades. Além de permitir extrair uma visão geral dos fenômenos dentro do contexto ambiental, social e tecnológico com relação à temática proposta.

\section{Categoria de análise}

A análise dos dados foi realizada por intermédio do método qualitativo, a mesma se deu através da observação, do uso de gravador de voz, de câmera fotográfica, de caderno de anotações, de modo que foi possível a identificação da problemática, a qual proporcionou a construção do referencial teórico, a coleta de dados a partir da entrevista e do questionário, além de contribuir na análise dos dados obtidos, favoreceu a interpretação dos fenômenos percebidos e finalmente a redação desse artigo.

\section{RESULTADOS E DISCUSSÃO}

Os dados coletados com o questionário aplicado aos produtores em questão estão relacionados na Tabela 1.

\section{Avaliação sobre o tipo de mulch utilizado}

No caso especifico do local de estudo predomina o mulch sintético dupla face preto/preto, branco/preto e prata/ preto.

Todos os entrevistados relataram usar como técnica de cultivo protegido a cobertura de solo pelo mulch de polietileno. Sendo que $75 \%$ dos entrevistados optaram pela variedade preto/preto para atender as necessidades do mercado interno, o qual apresenta uma menor exigência em relação à qualidade da fruta.

Esse tipo de mulch absorve uma parcela maior da luz do sol, promovendo um aumento na temperatura do solo, gerando muito calor à planta, chegando a causar queimaduras em folhas e fruto em regiões de radiação extrema, como informa MORAIS (2006). Nesse caso admite-se uma diminuição na qualidade da fruta colhida, uma vez que a região onde se localiza as áreas de produção em questão apresenta alta incidência de luz solar; por outro lado, o mulch do tipo preto/preto, diminui o custo de produção, tendo em vista que tem um valor de mercado menor em relação às demais variedades, por não possuir pigmentação, e por isso mais barato, podendo gerar uma lucratividade semelhante por um custo menor à obtida no cultivo do melão para o mercado externo, cuja exigência com a qualidade da fruta é mais elevada.

Tabela 1. Análise da tecnologia de mulching no cultivo do melão numa região de Mossoró/RN

\begin{tabular}{lc}
\multicolumn{1}{c}{ Variáveis } & $\%$ \\
Tipo de mulch (mercado interno) & 75 \\
preto/preto & 00 \\
branco/preto & 00 \\
prata/preto &
\end{tabular}

\begin{tabular}{lr}
\multicolumn{2}{c}{ Tipo de mulch (mercado externo) } \\
preto/preto & 00 \\
branco/preto & 50 \\
prata/preto & 75
\end{tabular}

Período de uso

5 anos 25

7 anos $\quad 50$

8 anos 25

Forma de retirada

remoção completa

remoção incompleta

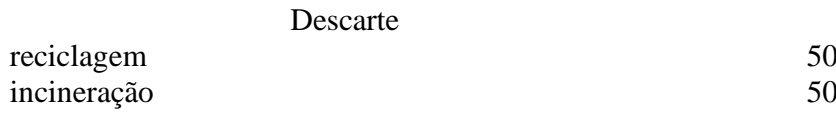

Reconhecimento da tecnologia

agrega valor

não agrega valor

Participação das empresas de reciclagem comprometidas

não comprometidas

Fonte: Dados da pesquisa.

Com relação às outras duas variedades de mulch utilizadas, $75 \%$ admitiram usar a variedade branco/preto e $50 \%$ usar o prata/preto, principalmente para o cultivo da fruta destinada ao mercado externo, como pode ser observado na Tabela 1.

Os filmes brancos e aluminizados apresentam maior capacidade de refletância de luz solar. Os filmes prateados refletem maior parte dos raios solares, transmitindo pouca energia para o solo, constituindo-se num dos materiais sintéticos mais adequados para regiões quentes, como é o caso da região Nordeste do Brasil, de acordo com MORAIS (2006). O fato de refletirem mais a luz solar incidente promovem menos injúrias à planta, acumulam menos calor no solo e consequentemente obtém-se uma fruta com mais qualidade, atendendo melhor as exigências do mercado externo.

Com isso, o uso adequado do tipo de mulch demonstra ser um ponto positivo na fruticultura, impactando 
indiscutivelmente no desenvolvimento da planta e melhoria da produção, quanto à qualidade e quantidade produzida.

\section{Avaliação sobre o período de uso do mulch de polietileno}

Observou-se que o uso de mulch de polietileno variou de cinco a oito anos de utilização contínua (Tabela 1). Segundo Machado (2011), o mulch é um material difícil de compactar e gera um grande volume de lixo, dificultando assim a decomposição de outros materiais orgânicos. É resistente aos decompositores como fungos e bactérias, degradando-se lentamente, levando aproximadamente 100 mil anos.

Considerando que o mulch utilizado na região em questão não é retirado completamente do solo após a colheita da fruta, fica claro que o meio ambiente é poluído há anos pelo seu resíduo, e isso pode gerar impactos diretamente sobre o solo onde a degradação de materiais orgânicos necessários à fertilidade deste, fica comprometida; além de incorrer na possível poluição de águas superficiais a partir do escoamento ou transporte desse material, proveniente de precipitações pluviométricas ou pela ação do próprio homem, para dentro de coleções de água situadas nas proximidades.

Demonstrando, portanto, que o mau uso do mulch, como por exemplo, a não retirada completamente do local de produção, independente do período em que é utilizado, acarreta danos ao ambiente como um todo, gerando diminuição da fertilidade do solo, poluição, até um possível desequilíbrio do ecossistema em questão, impactando de forma negativa a área de produção.

\section{Avaliação sobre maneiras de retirar o mulch do solo}

Quanto à questão dos informantes conhecerem uma maneira de retirar o mulch completamente do solo, $100 \%$ disseram que desconhecem (Tabela 1). Porém, já existem no mercado formas adequadas de usar essa tecnologia poluindo menos, ao mesmo tempo, que evita o comprometimento da fertilidade do solo, garantindo o uso correto do meio ambiente, como no caso dos filmes biodegradáveis destacados por AGROBIOFILM (2010). Também existem implementos agrícolas que fazem a retirada mecânica do mulch de forma eficaz, como os coletores hidráulicos.

O desconhecimento relatado acima demonstra de certa forma, uma falta de interesse e compromisso em preservar as propriedades do ambiente de trabalho, bem como da qualidade de vida dos envolvidos, sobressaindo apenas a questão da lucratividade imediata.

\section{Avaliação sobre o descarte do resíduo do mulch}

Metade (50\%) dos entrevistados respondeu que esse resíduo era destinado a empresas de reciclagem (Tabela 1), no entanto estas não tinham prazos para coletar os plásticos, deixando-os amontoados aguardando o dia da recolha desse material. Em média, a espera é bastante demorada, chegando próximo de um ano. Os outros $50 \%$ responderam que acumulava por meses em uma área livre, nas imediações, e quando formava um grande volume, utilizava-se da queima para dá um destino ao resíduo (Tabela 1). Percebe-se a exposição dos trabalhadores encarregados dessa queima e de todo ecossistema local aos riscos de doenças causadas pela produção de fumaça tóxica, como relata WOEHL JÚNIOR
(2011), gerando impactos negativos para os produtores, além de comprometer seu ambiente de trabalho, promovendo danos a longo prazo.

\section{Avaliação sobre a tecnologia de mulching}

Todos os produtores concordaram que a tecnologia trouxe melhorias (Tabela 1), e que estas estavam relacionadas com o aumento da qualidade da fruta, aumento da produção, aumento da qualidade de vida e melhoras nas condições de trabalho, uma vez que a capina foi dispensada. Como é demonstrado na literatura, a aplicação de mulch para fruticultura faz a diferença no que diz respeito a maior produção, a melhor qualidade do fruto, a uma economia de água de irrigação entre outras, afirmações feitas por Miranda et al., (2003).

Para o autor, a maior temperatura e menor amplitude térmica no solo coberto podem aumentar a taxa de desenvolvimento das plantas e antecipar a colheita. Em regiões semiáridas a economia de água por redução nas perdas por evaporação é importante benefício da cobertura do solo, e as condições de temperatura e umidade criadas no solo proporcionam economia de fertilizantes pela maior disponibilidade de nutrientes.

Dessa forma, a utilização dessa tecnologia no cultivo do melão na região em destaque tem impacto positivo, sendo explicado devido às várias vantagens proporcionadas, como conseguir um ambiente que permita a produção da fruta em qualquer época do ano, com economia de água, redução do uso de agrotóxicos, isolamento de pragas e controle de intempéries climáticas, proporcionando um produto de maior qualidade e com menor agressão ao meio ambiente, corroboram Morais (2006); Figueiredo e Leite (2011).

\section{Avaliação da relação dos cooperados com as empresas de reciclagem}

Os cooperados e as empresas de reciclagem disponíveis apresentam uma relação sem compromisso entre as partes (Tabela 1), segundo informação dos mesmos. Desses, 50\% mencionaram que acha que o motivo está ligado a dificuldade das empresas em se deslocar até suas áreas devido a grande oferta de material plástico de outras fontes. Os outros $50 \%$ relataram que um dos motivos, parte da falta de iniciativa e interesse em estabelecer parcerias.

Sendo assim, leva-se a crer que o fato de não existir prazos para que estas empresas coletem o mulch residual, parte principalmente do interesse e responsabilidade dos donos da terra em buscá-las como alternativa para o descarte desse resíduo, uma vez que os mesmos não se mostraram dispostos para resolver o problema referido, que dessa forma, acaba tomando dimensões maiores a partir da realização da queima desse material, incorrendo em graves danos ambientais e à saúde pública.

De acordo com a legislação, Política Nacional de Resíduos Sólidos (PNRS) Lei $\mathrm{n}^{\mathrm{o}}$ 12.305/10 é de responsabilidade de todos dá um destino correto aos resíduos sólidos produzidos e, nesse caso, os produtores, principais envolvidos, não se enquadram nos princípios dessa lei, bem como os fabricantes e comerciantes deste produto. 
Este fato vai de encontro à logística equilibrada na área de produção, podendo gerar um custo elevado devido ao acúmulo de lixo.

\section{Avaliação de investimentos no âmbito social da comunidade}

De acordo coma certificação de comércio justo, a cooperativa é bonificada em dinheiro sempre que atende a todos os pré-requisitos da certificação, de modo que esse bônus deva ser revertido em bens para comunidade, e por intermédio dessa bonificação a comunidade foi contemplada com um centro digital para todos os cooperados e seus familiares, comportando dez microcomputadores com acesso a internet, fazendo jus, portanto, à certificação pelo selo Fair Trade para cultura do melão (ARAÚJO, 2009).

Nesse ponto, observa-se impacto positivo com o auxílio da tecnologia implantada para a cultura do melão. $\mathrm{O}$ aumento da produtividade com qualidade gerou renda e inclusão social aos cooperados.

\section{CONCLUSÕES}

Todos os entrevistados utilizam a tecnologia de mulching para o cultivo do melão.

Os tipos de mulch utilizados na área de produção são de dupla face preto/preto, branco/preto e prata/preto, sendo utilizado desde os últimos oito anos.

Todos os produtores mencionaram não conhecer uma maneira de retirar o mulch completamente do solo.

A reciclagem é utilizada como forma de descartar o resíduo do mulch, bem como, a prática da incineração.

Não existe compromisso na relação entre os cooperados e as empresas de reciclagem.

$\mathrm{O}$ uso de tecnologia mulching trouxe melhorias a $100 \%$ dos cooperados;

O centro digital promoveu a inclusão social dos cooperados e suas famílias.

\section{REFERÊNCIAS BIBLIOGRÁFICAS}

AGROBIOFILM. Workshop agrobiofilm, 2010.Disponível em:

<http://www.agrobiofilm.eu/pt/noticia_geral/188>Acess o em: 02 jan. 2015.

ARAGÃO, F. A. S.; ÁVILA, A. C. D. Inimigo Mortal. Embrapa Hortaliça, 2003. Disponível em:<http://www.grupocultivar.com.br/site/content/artigo s/artigos.php?id=492> Acesso em: 10 dez. 2014.

ARAÚJO, M. Rio Grande do Norte é o primeiro a certificar melão no mundo. Agência Sebrae de Notícias. 2009. Disponível

em:<http://www.agenciasebrae.com.br>Acessoem: 10 dez. 2014.

ARAÚJO, M.L.M.N. Impactos ambientais nas margens do Rio Piancó causados pela agropecuária. Revista Brasileira de Gestão Ambiental. v.4, n.1, p. 1333,janeiro/dezembro de 2010.
BRAGA SOBRINHO, R; GUIMARÃES, J.A; FREITAS, J. A. D; TERAO, D. Produção integrada de melão. Embrapa Agroindústria Tropical $1^{\mathrm{a}}$ edição, Fortaleza, CE. 2008.

BEZERRA, J.E. Desenho territorial dos trabalhadores da fruticultura no município de Mossoró (RN). Revista OKARA: Geografia em debate, João Pessoa, v.6, n.1, p. 99108, 2012.

CAMPELO, A. R.; AZEVEDO, B. M.; NASCIMENTO NETO, J. R.; VIANA, T. VA.; PINHEIRO NETO, L. G.; LIMA, R. H. Manejo da cultura do melão submetida a frequência de irrigação e fertirrigação com nitrogênio. Hortic. Bras., v. 32, n. 2, p. 138-144, 2014.

FIGUEIREDO, G.; LEITE. C. Tipos de estruturas plásticas utilizadas para cultivo em ambiente protegido. Casa da agricultura, v.14, n. 2, p. 9-10, 2011.

DANTAS, I. C.; OLIVEIRA, C. W.; SILVA, F. L.; SANTOS, F. S. S.; MARCO, C. A. Produção de melão amarelo sob diferentes densidades de plantio. Revista Brasileira de Agricultura Irrigada, v. 7, n. 1, p. 74-84, 2013.

DIAS, V. G. Crescimento, fisiologia e produção do meloeiro "pele de sapo" cultivado sob diferentes lâminas de irrigação. Campina Grande, Universidade Estadual da Paraíba, 2014. 84f. (Dissertação de Mestrado em Ciências Agrárias).

FREITAS, L. D. A.; FILGUEIRÊDO, V. B.; PORTO FILHO, F. Q.; COSTA, J. C.; CUNHA, E. M. Crescimento e produção do meloeiro cultivado sob diferentes níveis de salinidade e nitrogênio. Revista Brasileira de Engenharia Agrícola e Ambiental, v. 18, (suplemento), p. S20 - S26, 2014.

INSTITUTO BRASILEIRO DE GEOGRAFIA E ESTATÍSTICA - IBGE, Levantamento sistemático da produção agrícola. 2012.

LEITE, S.P.; SILVA, C.R.; HENRIQUES, L.C. Impactos ambientais ocasionados pela agropecuária no Complexo Aluízio Campos. Revista Brasileira de InformaçõesCientíficas. V.2, n.2, p.59-64, 2011.

MACHADO, R. C. Plástico e meio ambiente uma relação possível? 2011. Disponível em: <http://www.cienciaecultura.ufba.br/agenciadenoticias/o piniao/plasticoe-meio-ambiente-uma-relacao-possivel> Acesso em: 02 jan. 2015.

MIRANDA, N. O; MEDEIROS, J. F.; NASCIMENTO, I. B.; ALVES, L.P. Produtividade e qualidade de frutos de melão em resposta à cobertura do solo com plástico preto e ao preparo do solo.Hortic. Bras. v.21 n.3 Brasília. 2003.

MORAIS, E. R. C. Influência das condições climáticas e da cobertura plástica do solo no crescimento e 
produtividade do meloeiro.. Campina Grande, Universidade Estadual da Paraíba, 2006. 161f. (Tese de Doutorado em Recursos Naturais).

PNRS - Política Nacional de Resíduos Sólidos. Disponível em:<http://www.mma.gov.br/pol\%C3\%ADtica-deres\%C3\%ADduos-s\%C3\%B3lidos>Acesso em fev. 2015.

ROSENBERG, N.J. Microclimate: the biological environment. New York: John Wiley, 1974, 315p.
SOUZA JÚNIOR, R. F.; OLIVEIRA, F. H. T.; SANTOS, H. C.; FREIRE, F. J. ARRUDA, J. A. Frações de fósforo inorgânico do solo e suas correlações com o fósforo quantificado por extratores e pelo milho. Revista Brasileira de Ciência do Solo, v. 36, n. 1, p. 159-169, 2012.

WOEHLJÚNIOR, G. Perigo letal queimar lixo plástico no quintal, 2011. Disponível em: <http://rabugio.blogspot.com.br/2011/09/o-perigo-dequeimar-lixo-plasticono.html>Acesso em: 13 jan. 2015. 